\title{
Comparison of physical work capacity and systolic time intervals with ventricular inhibited and atrial synchronous ventricular inhibited pacing
}

\author{
IB KRUSE, LARS RYDÉN \\ From the Departments of Anaesthesiology and Medicine, Central Hospital, Skövde, Sweden
}

SUMMARY Sixteen patients with a non-invasively programmable pacemaker (Medtronic 2409) were examined with the unit in ventricular inhibited (VVI) and atrial synchronous ventricular inhibited (VDT/I) mode, respectively. Maximal exercise capacity was determined by means of bicycle ergometry. Work load was increased in steps of 10 watts each minute. Atrial and ventricular rates, brachial artery pressure, and respiratory rate were studied at rest and during exercise while systolic time intervals were determined at rest. There was an important increase in maximal exercise capacity when changing from VVI to VDT/I pacing. The extent of improvement was the same for patients above and below the age of 65 years. At comparable work loads VDT/I pacing resulted in significantly lower atrial rates than VVI pacing. Systolic time intervals did not differ between VVI and VDT/I pacing apart from an increase in left ventricular ejection time index with VDT/I pacing. Systolic time intervals and maximal exercise capacity with VVI pacing did not correlate with the increase in exercise capacity induced by VDT/I pacing. Physical performance can be significantly improved by VDT/I pacing in both young and old patients. Exercise capacity on VVI pacing cannot predict the possible benefit of change to VDT/I pacing.

During recent years there have been many reports on the successful clinical use of electrodes for transvenous atrial pacing and sensing. ${ }^{1-3}$ Thus, one of the main obstacles to the more widespread use of physiological pacing has been overcome. ${ }^{4}$ For many patients with complete heart block and intact sinus node function, the most effective mode of pacing should be the atrial synchronous, and beneficial haemodynamic effects of this type of pacing have been described. ${ }^{56}$

To our knowledge, systematic studies comparing the physical work capacity during ventricular inhibited $(\mathrm{VVI})^{7}$ and atrial synchronous pacing (VAT; VDT/I) have not been published. One explanation may be that the use of the latter mode of pacing is, as yet, limited. ${ }^{4}$ Another comes from the difficulties that exist in comparing two different types of pacemakers when this either necessitates investigation with the pacemaker exteriorised or before and after the exchange of an implanted pacemaker. Recently, however, we described an atrial synchronous ventricular inhibited pacemaker offering unique investigational opportunities,

Received for publication 19 January 1981 being non-invasively programmable to either VVI or atrial synchronous ventricular inhibited (VDT/I) pacing' and the aim of the present study was to compare the maximal physical work capacity with these two modes of pacing. The results have been used to study factors which could predict a possible beneficial effect of VDT/I pacing in a particular patient. The determination of systolic time intervals is a convenient method of non-invasive evaluation of cardiac performance ${ }^{10}$ and a secondary aim was to investigate whether these could be used to predict the possible beneficial effects of a change from VVI to VDT/I pacing.

\section{Subjects and methods}

\section{PATIENTS}

There were 16 patients (Table 1 ). The current pacemaker was implanted at least one week before the investigation. Some patients had previously been paced with another VDT/I pacemaker, explaining the varying duration of this mode of pacing. At the time of study none of the patients showed clinical signs of myocardial dysfunction apart from the arrhythmia. 
Table 1 Clinical characteristics of patients

\begin{tabular}{|c|c|c|c|c|c|c|}
\hline $\begin{array}{l}\text { Case } \\
\text { no. }\end{array}$ & $\begin{array}{l}\text { Age } \\
(y)\end{array}$ & Sex & Heart disease & $\begin{array}{l}\text { Duration of } \\
\text { VDT/I pacing } \\
\text { before test (mth) }\end{array}$ & $\begin{array}{l}\text { Pacing mode first } \\
\text { exercise test }\end{array}$ & Drugs \\
\hline 1 & 64 & $\mathbf{M}$ & $\operatorname{AVCD} 3^{\circ}$ & 32 & VVI & - \\
\hline 2 & 66 & $\mathrm{~F}$ & $\operatorname{AVCD} 3^{\circ}$ & 31 & VDT/I & $\begin{array}{l}\text { Quinidine } 1.2 \mathrm{~g}, \\
\text { digoxin } 0.25 \mathrm{mg}\end{array}$ \\
\hline 3 & 61 & $\mathrm{~F}$ & $\operatorname{AVCD} 3^{\circ}$ & 30 & VVI & - \\
\hline 4 & 67 & $\mathbf{F}$ & $\operatorname{AVCD}^{\circ}$ & 29 & VVI & - \\
\hline 5 & 60 & $\mathbf{M}$ & $\begin{array}{l}\text { AVCD } 2-3^{\circ} \text {, } \\
\text { ventricular arrhythmia }\end{array}$ & 24 & VDT/I & $\begin{array}{l}\text { Quinidine } 1.2 \mathrm{~g} \\
\text { digoxin } 0.25 \mathrm{mg}\end{array}$ \\
\hline 6 & 59 & $\mathbf{F}$ & $\operatorname{AVCD} 3^{\circ}$ & 16 & VVI & - \\
\hline 7 & 50 & $\mathbf{M}$ & $\operatorname{AVCD} 3^{\circ}$ & $1 \cdot 5$ & VVI & - \\
\hline 8 & 59 & $\mathbf{M}$ & $\operatorname{AVCD} 3^{\circ}$ & 2 & VVI & - \\
\hline 9 & 57 & $\mathbf{M}$ & $\operatorname{AVCD} 3^{\circ}$ & 0.25 & VDT/I & - \\
\hline 10 & 65 & $\mathbf{M}$ & $\operatorname{AVCD} 3^{\circ}$ & 0.25 & VDT/I & - \\
\hline 11 & 79 & $\mathbf{F}$ & $\begin{array}{l}\text { AVCD } 3^{\circ}, \\
\text { hypertension }\end{array}$ & 0.75 & VDT/I & $\begin{array}{l}\text { Digoxin } 0.25 \mathrm{mg} \text {, } \\
\text { frusemide } 40 \mathrm{mg}\end{array}$ \\
\hline 12 & 65 & $\mathbf{M}$ & $\begin{array}{l}\text { AVCD 2-3', } \\
\text { aortic stenosis }\end{array}$ & 0.5 & VDT/I & Digoxin $0.25 \mathrm{mg}$ \\
\hline 13 & 65 & $\mathbf{F}$ & $\operatorname{AVCD~}^{\circ}$ & 1 & VDT/I & - \\
\hline 14 & 71 & $\mathbf{M}$ & $\begin{array}{l}\text { AVCD } 3^{\circ}, \\
\text { hypertension }\end{array}$ & 1 & VDT/I & $\begin{array}{l}\text { Hydrochlorthiazide } 50 \mathrm{mg} \text {, } \\
\text { amiloride } 5 \mathrm{mg} \\
\text { digoxin } 0.25 \mathrm{mg}\end{array}$ \\
\hline 15 & 60 & $\mathbf{M}$ & $\begin{array}{l}\text { Sarcoidosis } \\
\text { with AVCD } 3^{\circ}\end{array}$ & 1 & VVI & $\begin{array}{l}\text { Digoxin } 0.25 \mathrm{mg} \text {, } \\
\text { frusemide } 40 \mathrm{mg} \text {, } \\
\text { prednisolone } 10 \mathrm{mg}\end{array}$ \\
\hline \multirow[t]{2}{*}{16} & 81 & $\mathrm{~F}$ & $\operatorname{AVCD} 3^{\circ}$ & 1.5 & VVI & Levothyroxine $0.1 \mathrm{mg}$ \\
\hline & \multicolumn{3}{|c|}{ Mean 64} & Mean 10.7 & & \\
\hline
\end{tabular}

AVCD, atrioventricular conduction defect; $2-3^{\circ}$, second to third degree.

THE PACEMAKER

The pacemaker (Medtronic 2409) has previously been described in detail. ${ }^{9}$ Briefly, it is an atrial synchronous ventricular inhibited unit with ventricular escape rates of $50,60,70$, or $80 /$ minute and a maximum atrial synchronous rate of $100,125,150$, or $175 /$ minute (in the first units the maximal programmable rate was 150 / minute: cases 7 and 8 ).

The rates can be non-invasively programmed. When the back-up rate is programmed, the mode is also programmed to VVI at the selected rate. Programming the upper rate limit simultaneously programs the mode to VDT/I without changing the previously programmed back-up rate. The pacemaker provides a constant PQ delay of 120 milliseconds when in the atrial synchronous mode. When the atrial rate of the patient reaches the programmed upper rate limit of the pacemaker blocking of conducted impulses occurs occasionally. With increasing atrial rate the frequency of blocked impulses increases and the stimulation interval is constrained so as to maintain it within the programmed upper rate limit.

\section{EXERCISE TESTS}

Exercise tests were performed on a calibrated electrically braked bicycle ergometer (Siemens-Elema,
Sweden). A 12 lead electrocardiogram, brachial artery cuff pressure, and respiration rate were recorded in the supine position before exercise. Thereafter the patient was seated on the bicycle and, after an electrocardiogram at rest, exercise was started at a load of 30 watts for the women and 50 watts for the men. The load was increased stepwise each minute by 10 watts until the patient could not continue because of exhaustion, severe angina, or ventricular tachycardia. This procedure is a sensitive way of determining the exercise tolerance of cardiac patients. ${ }^{112}$ The patient then resumed the supine position. Systolic brachial artery cuff pressure and respiration rate were recorded during every second work load, during the final load, and four minutes after exercise. Electrocardiograms were obtained during the last 10 seconds on each work load, and directly after, and four minutes after exercise. In addition, the electrocardiogram was continuously monitored on an oscilloscope during the procedure. Ventricular and atrial rates were calculated from the elctrocardiograms. All exercise tests were performed during strictly standardised conditions by the same investigator. To rule out bias induced by noncomparable reasons for stopping exercise, such an investigation should preferably be performed with the investigator unaware of the pacing mode. Since this was impossible the patients performed 


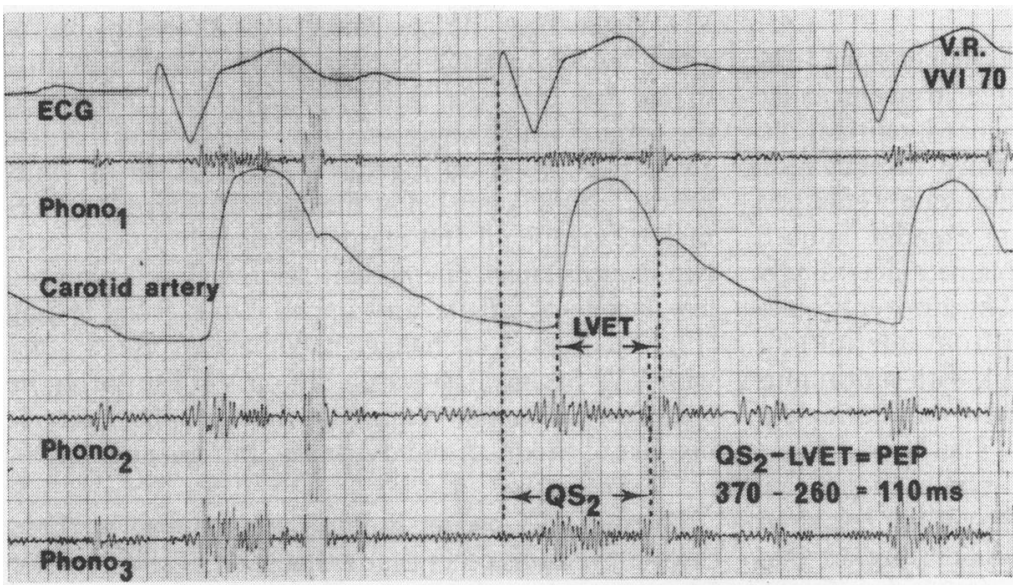

Fig. 1 Definition of systolic time intervals used in the present study. Electromechanical systole $\left(Q S_{2}\right)$ represents the time from the point on the electrocardiogram when the upstroke after the pacemaker artefact intersects the isoelectric line to the aortic component of the second heart sound. LVET, left ventricular ejection time; $P E P$, pre-ejection period. a maximal work load rather than stopping at a predetermined submaximal level of effort or because of slight discomfort such as tiredness or dyspnoea.

\section{SYSTOLIC TIME INTERVALS}

Systolic time intervals were determined in 11 of the cases as outlined by Weissler and Garrard. ${ }^{1314}$ The carotid artery pulse curve was recorded on a Mingograph 82 at a paper speed of $100 \mathrm{~mm} / \mathrm{s}$ by means of a pressure transducer, EMT $510 \mathrm{C}$ (Siemens-Elema, Sweden). A phonocardiogram was simultaneoulsy recorded from the third intercostal space at the left sternal edge. Electromechanical systole, left ventricular ejection time, and pre-ejection period were measured in $\mathrm{ms}$ as outlined in Fig. 1. Thus, electromechanical systole represents the time on the electrocardiogram from the intersection between the upstroke after the pacemaker artefact and the isoelectric line to the first high frequency vibrations of the aortic component of the second heart sound. The values given are the mean of 10 consecutive beats. For electromechanical systole, left ventricular ejection time, and pre-ejection period, the formulae given by Weissler and Garrard ${ }^{1314}$ have been used to correct for heart rate.

\section{PROCEDURE}

The patients were investigated as outpatients. A light meal was permitted in the morning. The patients were randomised to start with either VVI or VDT/I pacing (Table 1). For those starting with VVI pacing the reprogramming to this mode was performed upon arrival at the laboratory. The investigation started two hours later. After the determination of systolic time intervals the patient was exercised. Thereafter the pacemaker was reprogrammed and two hours later the investigation was repeated. When programming to VDT/I mode the highest obtainable atrial synchronous setting was used except in cases 9,13 , and 14 . These cases were programmed to 150 beats per minute. The patients could have a light meal but no coffee or tea between the first and second investigation. Any prescribed drugs were taken normally. Cases 2, 9, and 10 had their two tests on consecutive mornings but followed the same schedule (that is two hours between reprogramming and investigation). In case 12 the repeated exercise tests were performed with the maximal synchronous rate and drug treatment was adjusted between tests.

Student's $t$ test for paired differences was used for the statistical calculations, accepting $p<0.05$ as statistically significant.

\section{Results}

\section{PHYSICAL WORK CAPACITY}

The maximal exercise capacity with the VVI and VDT/I mode of pacing is shown in Fig. 2 and Table 2. There was a $20 \%$ mean increase in exercise capacity from $94 \pm 26$ watts (mean $\pm S D$ ) on VVI pacing, to $113 \pm 33$ watts on VDT/I pacing $(\mathrm{p}<0.001)$. All patients except two (cases 12 and 16) improved. When separating the patients into two groups according to age ( $>65$ years, $n=5$, mean age 73 years; $\leq 65$ years, $n=11$, mean age 61 years) both groups showed the same mean increase in exercise capacity of $20 \%$. The highest individual increase was found, however, among the younger patients.

Case 16, an 81-year-old woman, showed unaltered exercise capacity. The limiting factor was leg weariness and it was not felt that the patient reached her circulatory limit during either VVI or VDT/I pacing. Case 12 performed less work at the first exercise test during VDT/I compared with VVI pacing but later improved on VDT/I pacing. This patient is described in detail. 
Case report (case 12)

A 65-year-old man had had VVI pacemaker since 1974 because of intermittent second degree atrioventricular block. In 1977 the patient experienced palpitation, dyspnoea, and fatigue. A non-invasive investigation disclosed mild aortic stenosis with moderately enlarged heart. From 1978 he had moderate exercise-induced angina. In February 1979 he complained increasingly of dyspnoea, angina, and fatigue. The atrioventricular conduction defect had deteriorated from intermittent second degree to complete heart block with continuous paced rhythm. Since the atrial rate was normal, a VDT/I pacemaker was implanted. The back-up rate was $50 /$ minute and the maximal synchronous rate $150 /$ minute. One month later the patient felt less tired and dyspnoeic but complained of increasing angina. Exercise tests performed with the pacemaker in the VVI and VDT/I modes are shown in Fig. 3. Exercise performed with the pacemaker in VDT/I mode had to be stopped earlier ( 80 watts) than with VVI pacing ( 100 watts) because of severe angina beginning at a ventricular rate of about $135 \mathrm{bpm}$. With VVI pacing there was frequent retrograde atrial emptying owing to atrial contraction against closed atrioventricular valves, with resulting variation in the arterial pressure. It was still considered probable that the patient would benefit from
VDT/I pacing. The pacemaker was therefore reprogrammed to a maximal synchronous rate of $125 /$ minute so that the ventricular rate on exercise could not exceed the point at which angina started. The patient was also given metoprolol $50 \mathrm{mg}$ daily but because of sinus bradycardia at a rate below the back-up rate of the pacemaker, verapamil $160 \mathrm{mg}$ daily was substituted for it two months later. The patient improved and reported less dyspnoea, fatigue, and angina. On exercise testing (Fig. 3) he had an unchanged maximal exercise capacity with VVI pacing (100 watts) but on VDT/I pacing he reached 120 watts. This time he stopped exercise because of tiredness and dyspnoea, but not angina.

During VVI pacing exercise was stopped in three cases for reasons other than exhaustion (Table 2). Case 2 became pale and showed a fall in blood pressure at a work load of 80 watts, but on VDT/I pacing managed 100 watts with a normally increasing blood pressure. Case 16 has already been mentioned. Exercise had to be stopped in case 9 because of ventricular tachycardia. The case report on this patient follows.

Case report (case 9)

A 57-year-old man with complete heart block since

Table 2 Results of exercise test with VVI and VDT/I pacing

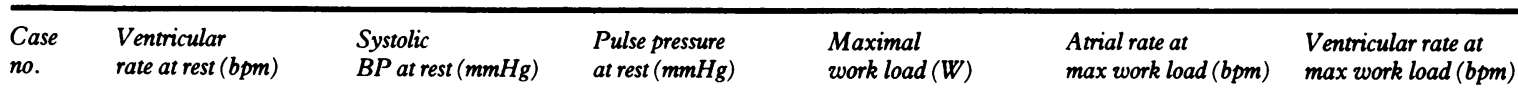

\begin{tabular}{|c|c|c|c|c|c|c|c|c|c|c|c|c|}
\hline & $V V I$ & $V D T / I$ & $V V I$ & $V D T / I$ & $V V I$ & $V D T / I$ & $V V I$ & $V D T / I$ & $V V I$ & $V D T / I$ & $V V I$ & $V D T / I$ \\
\hline 1 & 72 & 76 & 155 & 155 & 75 & 75 & 110 & 150 & 156 & 162 & 72 & 162 \\
\hline 2 & 70 & 67 & 140 & 155 & 65 & 80 & 80 & 100 & 99 & 112 & 70 & 112 \\
\hline 3 & 71 & 109 & 185 & 160 & 95 & 70 & 80 & 110 & 172 & 178 & 71 & 178 \\
\hline 4 & 71 & 85 & 175 & 165 & 80 & 75 & 70 & 90 & 170 & 175 & 71 & 175 \\
\hline 5 & 70 & 57 & 140 & 148 & 40 & 56 & 130 & 170 & 180 & 148 & 70 & 148 \\
\hline 6 & 70 & 80 & 115 & 120 & 25 & 40 & 80 & 110 & 172 & 174 & 70 & 174 \\
\hline 7 & 71 & 80 & 130 & 125 & 45 & 40 & 110 & 130 & 185 & 185 & 71 & 144 \\
\hline 8 & 71 & 100 & 130 & 120 & 50 & 30 & 130 & 150 & 172 & 172 & 88 & 135 \\
\hline 9 & 71 & 76 & 135 & 125 & 45 & 35 & 130 & 150 & 165 & 155 & 135 & 135 \\
\hline 10 & 69 & 72 & 160 & 165 & 65 & 75 & 120 & 140 & 174 & 174 & 69 & 174 \\
\hline 11 & 69 & 52 & 170 & 180 & 90 & 100 & 50 & 60 & 133 & 130 & 69 & 130 \\
\hline 12 & 70 & 60 & 130 & 135 & 30 & 40 & 100 & 80 & 165 & 150 & 70 & 150 \\
\hline
\end{tabular}

\begin{tabular}{|c|c|c|c|c|c|c|c|c|c|c|c|c|}
\hline $\begin{array}{l}13 \\
14 \\
15 \\
16\end{array}$ & $\begin{array}{l}71 \\
71 \\
71 \\
71\end{array}$ & $\begin{array}{r}82 \\
75 \\
89 \\
105\end{array}$ & $\begin{array}{l}185 \\
170 \\
130 \\
215\end{array}$ & $\begin{array}{l}185 \\
205 \\
135 \\
200\end{array}$ & $\begin{array}{r}110 \\
80 \\
50 \\
130\end{array}$ & $\begin{array}{r}80 \\
105 \\
65 \\
100\end{array}$ & $\begin{array}{r}80 \\
80 \\
100 \\
60\end{array}$ & $\begin{array}{r}100 \\
100 \\
110 \\
60\end{array}$ & $\begin{array}{l}170 \\
168 \\
170 \\
165\end{array}$ & $\begin{array}{l}165 \\
170 \\
175 \\
172\end{array}$ & $\begin{array}{l}71 \\
71 \\
71 \\
71\end{array}$ & $\begin{array}{l}130 \\
130 \\
175 \\
172\end{array}$ \\
\hline $\begin{array}{l}\text { Mean } \\
\text { SD }\end{array}$ & $\begin{array}{l}71 \\
0.8\end{array}$ & $\begin{array}{l}79 \\
16\end{array}$ & $\begin{array}{r}154 \\
27\end{array}$ & $\begin{array}{r}155 \\
28\end{array}$ & $\begin{array}{l}67 \\
29\end{array}$ & $\begin{array}{l}67 \\
24\end{array}$ & $\begin{array}{l}94 \\
26\end{array}$ & $\begin{array}{r}113 \\
33\end{array}$ & $\begin{array}{r}164 \\
21\end{array}$ & $\begin{array}{r}162 \\
19\end{array}$ & $\begin{array}{l}76 \\
16\end{array}$ & $\begin{array}{r}152 \\
22\end{array}$ \\
\hline p & \multicolumn{2}{|c|}{$<0.05$} & \multicolumn{2}{|c|}{ NS } & \multicolumn{2}{|c|}{ NS } & \multicolumn{2}{|c|}{$<0.001$} & \multicolumn{2}{|c|}{ NS } & \multicolumn{2}{|c|}{$<0.001$} \\
\hline
\end{tabular}

BP, blood pressure; E, exhaustion; PVC, premature ventricular contraction; VT, ventricular tachycardia. 
October 1978 had had Adams-Stokes attacks. Despite a VVI pacemaker he continued to have attacks of giddiness and also complained of exertional dyspnoea. Apart from the conduction defect there were no signs of cardiac disease. Retrograde atrial emptying and loss of the capability of an increase in heart rate during exercise were considered the probable causes of his symptoms. In May 1979 a VDT/I pacemaker with a back-up rate of 50/minute and a maximal synchronous rate of 150/minute was substituted for the VVI pacemaker. After this the symptoms vanished and the patient remained well. An exercise test was performed with the pacemaker in the VVI and VDT/I mode, respectively. As can be seen from Fig. 4 an alternative explanation for the remaining attacks of dizziness during VVI pacing is possible. When exercising with the pacemaker in the VVI mode, he developed ventricular ectopic beats at a work load of 110 watts. The exercise test was stopped because of runs of ventricular tachycardia with severe dyspnoea and fatigue at a work load of 130 watts. When performing exercise with the pacemaker in the VDT/I mode there was no ventricular tachyarrhythmia despite the higher work load (150 watts).

Only one patient stopped exercise during VDT/I pacing because of symptoms other than exhaustioncase 12 , described in detail above.

\begin{tabular}{|c|c|c|c|c|c|c|}
\hline \multirow{2}{*}{$\begin{array}{l}\text { Programmed } \\
\text { max atrial } \\
\text { synchronous } \\
\text { rate (bpm) } \\
V D T \mid I\end{array}$} & \multicolumn{2}{|c|}{$\begin{array}{l}\text { Systolic BP } \\
\text { at maximal } \\
\text { work load }(\mathrm{mmHg})\end{array}$} & \multicolumn{2}{|c|}{$\begin{array}{l}\text { Respiration at } \\
\text { max work load } \\
\text { (rate/min) }\end{array}$} & \multicolumn{2}{|c|}{$\begin{array}{l}\text { Reason for } \\
\text { terminating } \\
\text { work }\end{array}$} \\
\hline & $V V I$ & $V D T / I$ & $V V I$ & $V D T / I$ & $V V I$ & $V D T / I$ \\
\hline 175 & 200 & 215 & 32 & 36 & & E \\
\hline 175 & 130 & 195 & 32 & 32 & $\begin{array}{l}\text { BP drop, } \\
\text { pallor }\end{array}$ & $\mathrm{E}$ \\
\hline 175 & 180 & 190 & 30 & 30 & $\mathrm{E}$ & $\mathrm{E}$ \\
\hline 175 & 205 & 190 & 28 & 32 & E & E \\
\hline 175 & 180 & 185 & 30 & 32 & $\mathrm{E}$ & $\mathrm{E}$ \\
\hline 175 & 165 & 175 & 32 & 34 & & E \\
\hline 150 & 155 & 160 & 44 & 44 & E E & E \\
\hline 150 & 210 & 215 & 32 & 34 & E+PVC & $\mathrm{E}$ \\
\hline 150 & 195 & 190 & 36 & 44 & VT & $\mathrm{E}$ \\
\hline 175 & 215 & 200 & 34 & 32 & E & E \\
\hline 175 & 190 & 185 & 36 & 44 & $\mathrm{E}$ & $\mathrm{E}$ \\
\hline 175 & 175 & 130 & 36 & 40 & $\mathrm{E}$ & $\begin{array}{l}\text { Severe } \\
\text { angina } \\
\text { pectoris }\end{array}$ \\
\hline 150 & 215 & 245 & 28 & 28 & $\mathrm{E}$ & $\mathrm{E}$ \\
\hline 150 & 210 & 230 & 28 & 36 & $\mathrm{E}$ & $\mathrm{E}$ \\
\hline 175 & 150 & 175 & 32 & 32 & $\mathrm{E}$ & $\mathrm{E}$ \\
\hline 175 & 220 & - & 28 & 30 & Fatigue i & $n$ legs \\
\hline - & 183 & 192 & 32 & 35 & & \\
\hline- & 24 & 28 & 4 & 5 & & \\
\hline - & $\mathrm{N}$ & & & .01 & & \\
\hline
\end{tabular}

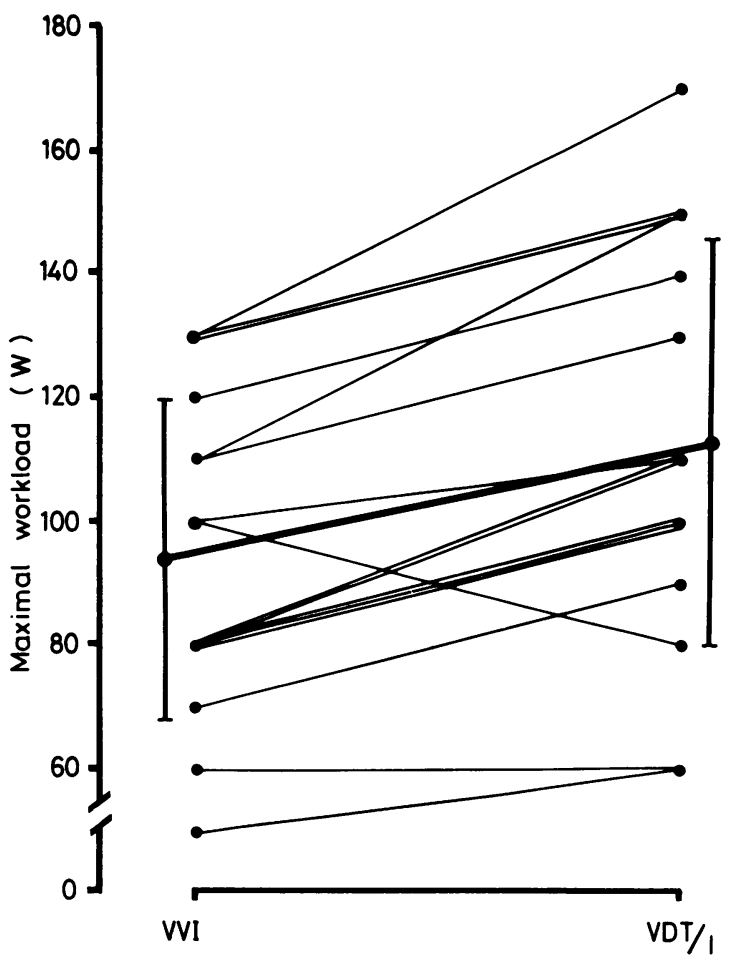

Fig. 2 Maximal work capacity with VVI and VDT/I pacing. Individual data together with mean $\pm S D$ for the group (thick line).

The respiration rates and systolic pressures during maximal work in the two pacing modes differed significantly $(p<0.01)$ at the end of exercise, the difference in absolute figures being small.

The atrial rates during all work levels were significantly higher with VVI than with VDT/I pacing (Fig. 5). Comparing the two modes of pacing, there was no statistically significant difference in systolic and diastolic pressure at rest or in systolic pressure and respiration rate at maximal work load (Table 2). The working capacity during VVI pacing and the difference on changing to the VDT/I mode showed no correlation.

\section{SYSTOLIC TIME INTERVALS}

Systolic time interval indices and pre-ejection period divided by left ventricular ejection time during VVI and VDT/I pacing are shown in Fig. 6 and 7. The only statistically significant difference was an increase in left ventricular ejection time index from $381 \pm 25 \mathrm{~ms}$ to $400 \pm 22 \mathrm{~ms}(\mathrm{p}<0.01)$ with the institution of VDT/I pacing. Indices for electromechanical systole, preejection period, and pre-ejection period divided by left ventricular ejection time did not show any uniform changes. No correlation could be shown between the different systolic time intervals during VVI pacing and 


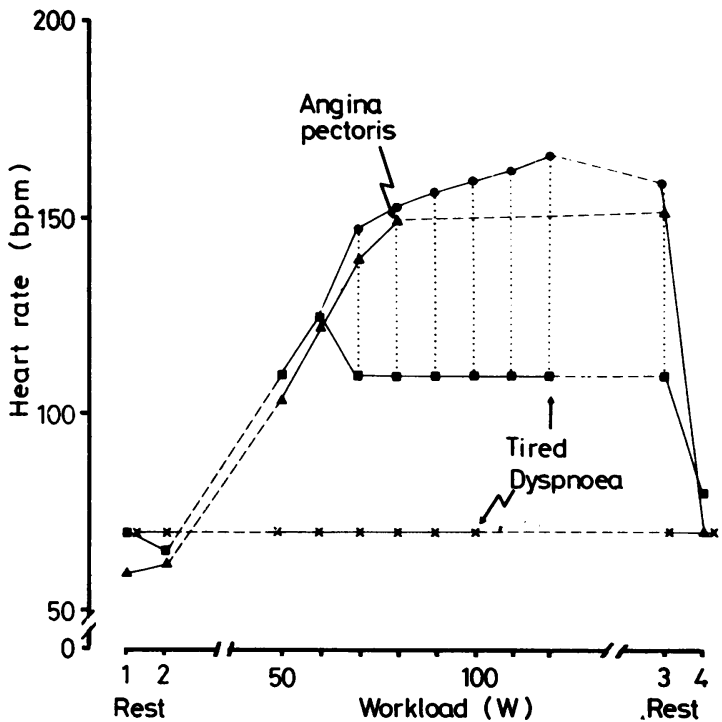

Fig. 3 Results of repeated exercise tests in case 12. See text for details. $x$, ventricular rate with VVI pacing 7 une 79 and February 80; $\Delta$, atrial and ventricular rate with VDT/I pacing f une 79; $\boxminus$, ventricular rate with VDT/I pacing February 80 ; $\bullet$, atrial rate with VDT/I pacing when exceeding ventricular rate February 80; dotted line indicates the gap between atrial and ventricular rate resulting from blocking in the pacemaker; 1 and 2 , supine and sitting at rest; 3 and 4 , directly after and four minutes after exercise.

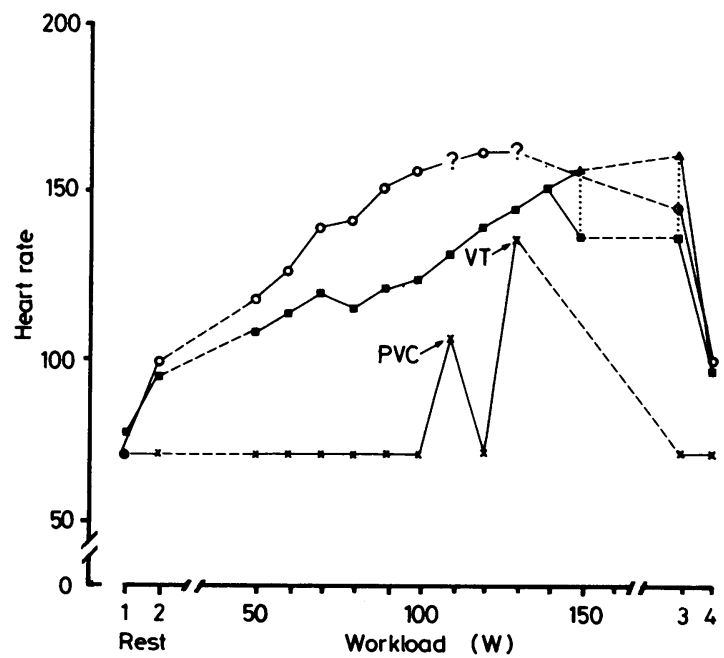

Fig. 4 Results of exercise tests in case 16. See text for details. $x$, ventricular rate with VVI pacing; $\bigcirc$, atrial rate with $V V I$ pacing; $\mathbf{- 1}$, ventricular rate with VDT/I pacing; $\mathbf{\Lambda}$, atrial rate with VDT/I pacing when exceeding ventricular rate. Dotted line indicates the gap between atrial and ventricular rate due to blocking in the pacemaker.

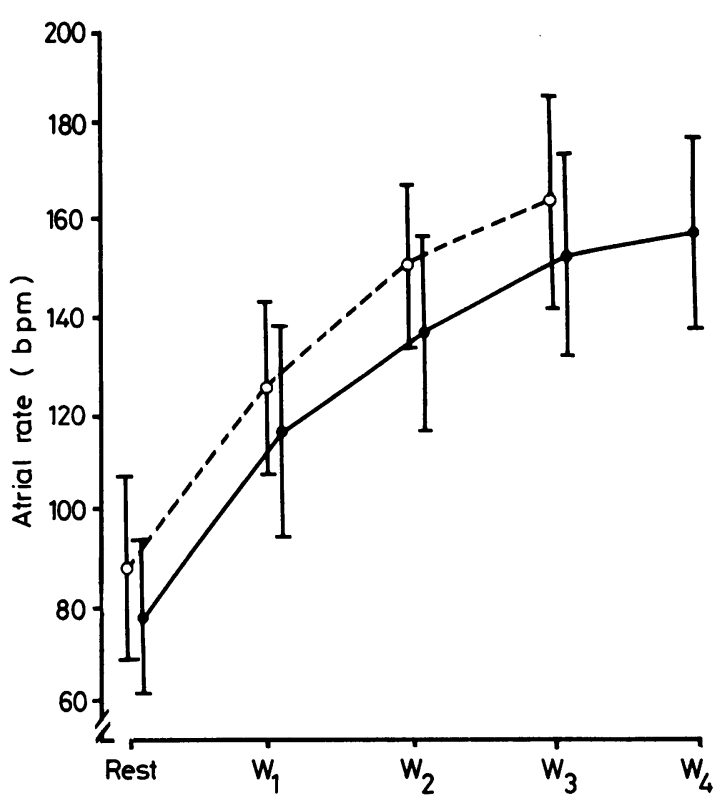

Fig. 5 Mean $( \pm S D)$ atrial rate with $V V I(\bigcirc)$ and $V D T / I(\bullet)$ pacing at rest, $50 \%, 75 \%$, and $100 \%\left(W_{3}\right)$ of the maximal work load obtained with VVI pacing. $W_{4}$ represents the maximal work load with VDT/I pacing. The differences are all significant: $\left(W_{1}\right.$ : $\left.p<0.001 ; W_{2} ; p<0.01 ; W_{3}: p<0.05\right)$.

the resulting relative or absolute change in exercise capacity after reprogramming to the VDT/I mode.

\section{Discussion}

Changing from fixed rate to atrial synchronous pacing improves the haemodynamic response to physical work in patients with complete heart block because of the restoration of a normal temporal relation between atrial and ventricular contraction and of the capacity to increase heart rate during exercise ${ }^{6}{ }^{15}$ though to what extent this haemodynamic improvement results in an increased exercise capacity is not certain.

The present data show that physical working ability is better with VDT/I than with VVI pacing. Though a higher degree of exhaustion was produced with VDT/I than with VVI pacing at the end of exercise it still seems reasonable to conclude that the main reason for the differences in physical working capacity was the change in pacing mode. The improvement varied in different patients but was substantial in most of them. Our results suggest that older patients may be expected to derive the same benefit from VDT/I pacing as younger ones.

The time before the exercise tests was considerably longer with VDT/I than with VVI pacing in our patients. It can be questioned whether equally long periods on the two pacing modes would result in less 

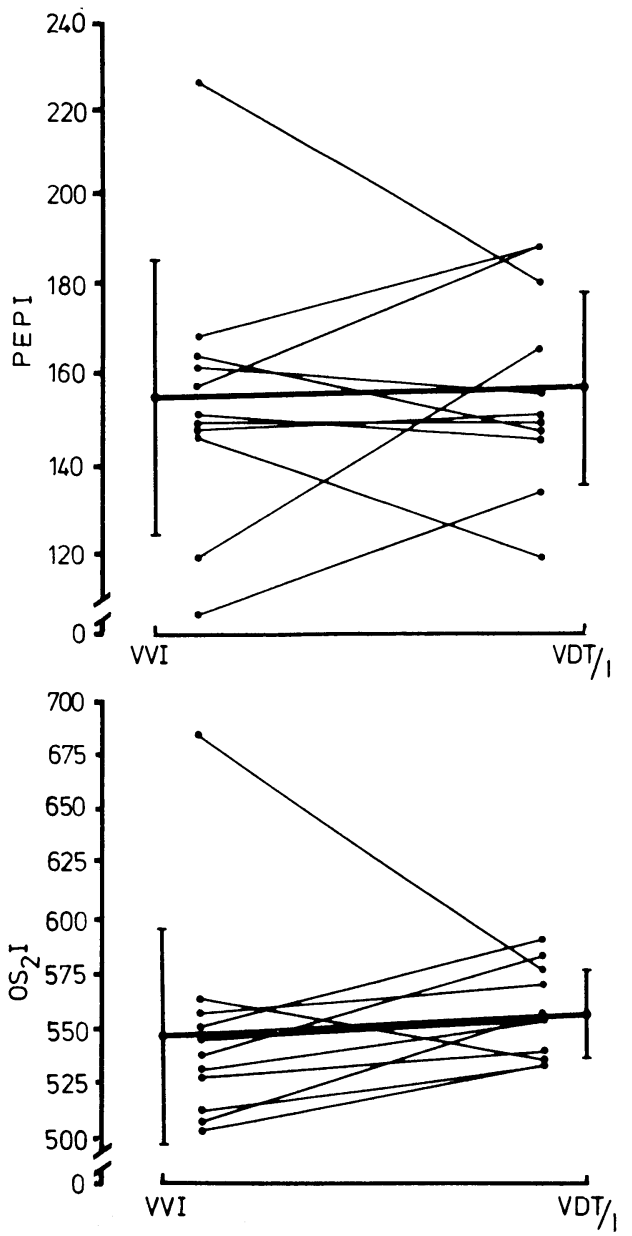

Fig. 6 Pre-ejection period index (PEPI) and electromechanical systole index $\left(Q S_{2} I\right)$ with VVI and VDT/I pacing. Individual data together with mean $\pm S D$ for the group (thick line).

difference in exercise capacity. Adaptation, however, to different pacing modes occurs rapidly. ${ }^{616}$ Furthermore, patients paced in the VVI mode for longer periods before being changed to the VDT/I mode showed even greater improvement in exercise capacity (Kruse and Rydén, to be published).

The improvement in cardiac output produced by VDT/I pacing is dependent principally on heart rate increase at rates below $100 /$ minute, while at higher rates the atrial contribution to ventricular filling becomes more important. ${ }^{17-19}$ The value of atrial transport is greater in patients with poor myocardial function and valvular heart disease. ${ }^{20}$ But our results indicate that atrioventricular synchronous pacing may substantially improve even patients without signs of myocardial dysfunction.

Most patients do not seem to need a higher syn-
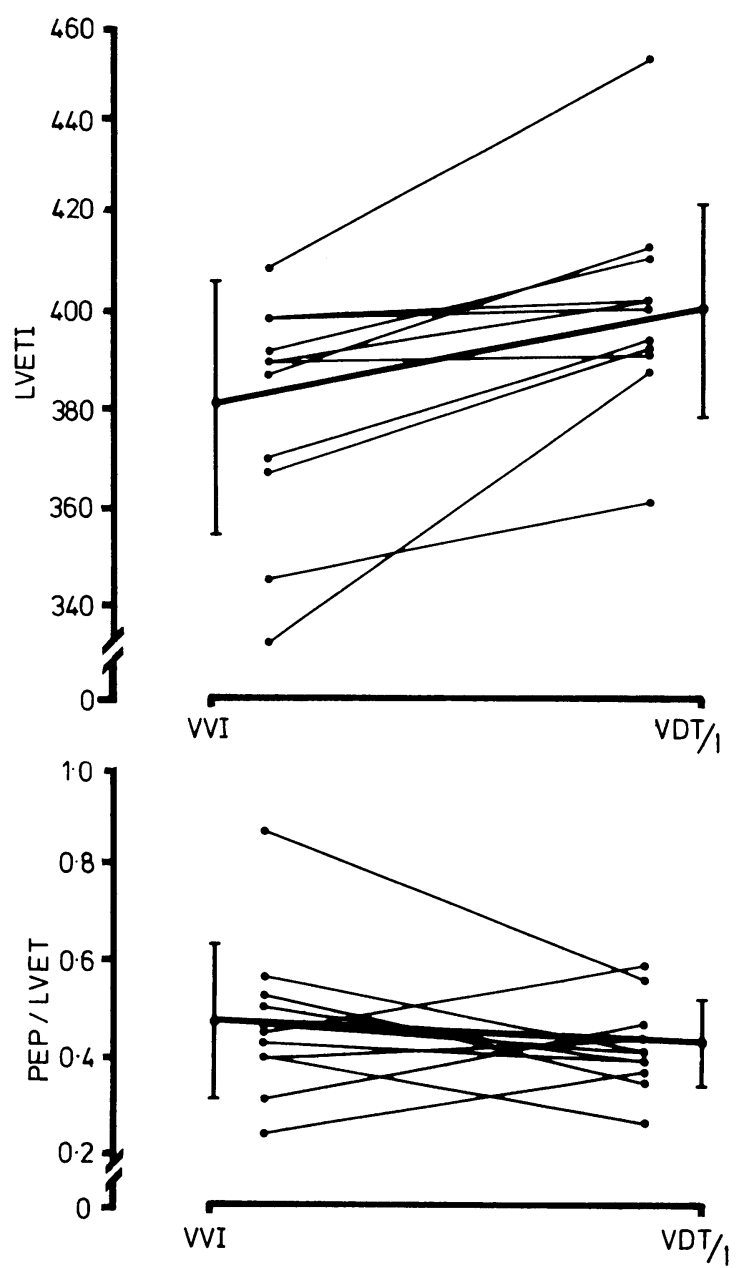

Fig. 7 Left ventricular ejection time index (LVETI) and pre-ejection period divided by left ventricular ejection time (PEP/LVET) with VVI and VDT/I pacing. Individual data and mean $\pm S D$ for the group (thick line).

chronous rate than 150/minute (Table 2, Fig. 5). Paced patients are often old and the maximal effective heart rate in a corresponding age group has been claimed to be 150 to $160 /$ minute. ${ }^{21}$ Some of our patients reached higher heart rates than 150 and seemed to benefit. This occurred during maximal exercise and in daily life such high levels of exercise and heart rate are unusual. The higher atrial rates during exercise with VVI pacing than with VDT/I pacing during corresponding work loads (Fig. 4) are probably caused by a higher sympathetic tone needed to maintain cardiac output during the former. Similar findings have been reported in patients with intermittent complete heart block when comparing exercise during sinus rhythm and periods of block. ${ }^{22} \mathrm{~A}$ practical implication is that the final syn- 
chronous rate setting of the pacemaker should not be based on the atrial rate reached in the exercise test during pacing in the VVI mode. Coronary heart disease has been considered a contraindication to atrial synchronous pacing because of the risk of provoking angina with high heart rates. ${ }^{6}$ But patients with coronary disease often have decreased myocardial compliance and should benefit from a correctly timed atrial contraction. Furthermore, their capacity to increase stroke volume is often limited, necessitating higher heart rates to maintain cardiac output during exercise. Angina usually does not occur below a critical heart rate. If the highest synchronous rate of the pacemaker can be adjusted to a level below this, the beneficial effects of VDT/I pacing can be made available for such patients also as shown in case 12 .

The elimination of exercise-induced ventricular tachycardia after the initiation of VDT/I pacing in case 9 is interesting. Case 8 also had ventricular premature contractions while exercised in the VVI but not in the VDT/I mode. When considering candidates for VDT/I pacing it is important to note that exercise tolerance with VVI pacing does not seem to predict the magnitude of possible improvement after the change of pacing mode, nor do systolic time intervals. Digital pulse plethysmography has been suggested as a method for selecting patients suitable for various modes of physiological pacing. ${ }^{23}$ Such convenient non-invasive methods could be of great clinical importance and the lack of correlation between systolic time intervals and changes in working capacity in the two pacing modes is disappointing. After the change to VDT/I pacing the only consistent difference, an increase in the left ventricular ejection time index, probably reflected an increased stroke volume. Different pacing modes may simultaneously produce several alterations in cardiac performance. Some of these, such as increased stroke volume or decreased sympathetic tone, may vary in extent from one patient to another with inconsistent effects on particular systolic time intervals. ${ }^{1314}$

\section{References}

1 Smyth NPD, Citron P, Keshishian JM, Garcia JM, Kelly LC. Permanent pervenous atrial sensing and pacing with a new J-shaped lead. $\mathcal{f}$ Thorac Cardiovasc Surg 1976; 72: 565-70.

2 El Gamal M, Van Gelder B. Preliminary experience with the Helifix electrode for transvenous atrial implantation. Pace 1979; 2: 444-54.

3 Kruse IB, Rydén L. Ydse BO. A new lead for transvenous atrial pacing and sensing. Clinical and electrophysiological experiences. Pace 1980; 3: 395-405.

4 Sutton R, Citron P. Electrophysiological and haemodynamic basis for application of new pacemaker technology in sick sinus syndrome and atrioventricular block. Br Heart f 1979; 41: 600-12.
5 Center S, Nathan D, Wu CY, Samet P, Keller W. The implantable synchronous pacer in the treatment of complete heart block. $\mathcal{F}$ Thorac Cardiovasc Surg 1963; 46: 744-53.

6 Karlöf I. Haemodynamic effect of atrial triggered versus fixed rate pacing at rest and during exercise in complete heart block. Acta Med Scand 1975; 197: 195-206.

7 Parsonnet V, Furman S, Smyth NPD. Implantable cardiac pace-makers status report and resource guideline. Pacemaker study group. Circulation 1974; 50: A-21-A-25.

8 Goldman BS, Parsonnet V. World survey on cardiac pacing. Pace 1979; 2: W-9, 10.

9 Kruse I, Rydén L, Duffin E. Clinical evaluation of atrial synchronous ventricular inhibited pacemakers. Pace 1980; 3: 641-50.

10 Weissler AM, Peeler RG, Roehll WH Jr. Relationships between left ventricular ejection time, stroke volume, and heart rate in normal individuals and patients with cardiovascular disease. Am Heart $\mathcal{F}$ 1961; 62: 367-78.

11 Lange-Andersen K, Shephard RJ, Denolin H, Varnauskas E, Masorini R. Fundamentals of exercise testing. Geneva: World Health Organization, 1971.

12 Aström H, Jonsson B. Design of exercise test, with special reference to heart patients. Br Heart f 1976; 38: 289-96.

13 Weissler AM, Garrard L. Systolic time intervals in cardiac disease (I). Mod Concepts Cardiovasc Dis 1971; 40: 1-4.

14 Weissler AM, Garrard L. Systolic time intervals in cardiac disease (II). Mod Concepts Cardiovasc Dis 1971; 40: 5-8.

15 Center S, Nathan DA. The synchronous pacer. Three years of clinical experience with 45 cases. Ann Surg 1966; 164: 862-6.

16 Karlöf I, Bevegård S, Ovenfors C-O. Adaptation of the left ventricle to sudden changes in heart rate in patients with artificial pacemakers. Cardiovasc Res 1973; 7: 322-30.

17 Martin RH, Cobb LA. Observations on the effect of atrial systole in man. $\mathcal{F}$ Lab Clin Med 1966; 68: 224-32.

18 Samet P, Castillo C, Bernstein WH. Hemodynamic sequelae of atrial, ventricular, and sequential atrioventricular pacing in cardiac patients. Am Heart $f$ 1966; 72: 725-9.

19 Brockman SK, Collins HA, Bloomfield DA, Sinclair Smith BC, Gobbel WG. Physiological studies and clinical experience in patients with synchronous and asynchronous pacemakers. $\mathcal{F}$ Thorac Cardiovasc Surg 1966; 51; 864-72.

20 Benchimol A. Significance of the contribution of atrial systole to cardiac function in man. Am $\mathcal{F}$ Cardiol 1969; 23: 568-71.

21 Astrand PO, Rodahl K. Textbook of work physiology. New York: McGraw Hill, 1970: 166-7.

22 Johansson BW. Complete heart block. Acta Med Scand 1966; 180, suppl 451 .

23 Fagrell B, Lindvall K. Non-invasive beat to beat analysis of stroke volume and digital pulse volume in patients with complete heart block and artificial pacing. Acta Med Scand 1979; 205: 185-90.

Requests for reprints to Dr Ib Kruse, Department of Anesthesiology, Central Hospital, S-541 85 Skövde, Sweden. 